\title{
WORD, CONCEPT AND SIGNIFICATION' IN A NEW NEW GUIDE BY LARA EGGER. GOING AGAINST THE READER' S EXPECTATIONS
}

\begin{abstract}
In our view, the main theme of the poem $A$ New New Guide by Lara Egger is linguistic relativity, leading to conceptual relativity but, paradoxically, also to the opposite view, the semantic universals frame, in an attempt to vouch for flexibility in thinking, beyond linguistic barriers and limitations. Using the instruments of pragma-stylistics, we envisage a hands-on text analysis, focusing on space markers, both deictic and anaphoric, in order to point out their contextual values which are of paramount importance in (re) configuring the common ground throughout the poem. The permanent negotiation of the common ground works programmatically against the reader's expectations, which is both intriguing and challenging. The poem's title itself signals the danger of the desemanticization of the term new, novelty becoming a purpose in itself; hence, in the poem we discover an original perspective on canonical art forms, life forms, tradition and myths.
\end{abstract}

Key words: word, concept, space markers, deictic, anaphoric, common ground

\section{Why this type of analysis and this poem?}

Lara Egger's A New New Guide is a poem with metalanguage as its major theme; being a reflection on language, and on semiosis, it accommodates ideas belonging both to linguistic relativity and relevance theories, on the one hand, and to semantic universals and minimalist semantics, on the other, reconciling these opposite viewpoints. Hence, the challenging title $A$ New New Guide refers to an equally linguistic and conceptual guide; the poem's theme seems to be the continuous quest for something unique, but, paradoxically, for trend-setters from the point of view of lifestyle and philosophy of life. The virtually perpetual new perspective implicitly expressed by the title (A [New [New [New [... [New [Guide]]]]]]) is in itself ambiguous, somewhere between a strictly denotational and literal understanding, and an ironical interpretation of the adjective:

\footnotetext{
"Faculty of Letters, University of Craiova, 13 A. I. Cuza Street, Craiova, Romania; e-mail: claudiagabrielapisoschi@yahoo.com

${ }^{1}$ We use the term in the meaning given by structuralist linguistics, i.e. the object in the extra-linguistic world picked out by a word.
} 
novelty is a condition of progress in thinking and communication, not a purpose in itself, but an objectively grounded necessity; a possible ironical interpretation of the title (triggering other ironical inferences throughout the text) arises from the incessant quest for new patterns to be imitated without actually internalizing their significance.

\section{Working hypothesis. Objectives and method used}

The poem argues indirectly in favor of new words, languages, possibly, implicitly, of new types of signs, since words frequently seem to have lost their power of expression because of conventionalization; they have become much too often form without meaning, or forms conveying a limited meaning, therefore limited concepts which hinder a genuine world knowledge since we gain knowledge through words:

[...] Sometimes at night,

I worry about what I'm missing,

simply because I don't know the word for it.

The thought, meaning, is turned from "substance" into "form" by words. The message to be found throughout the poem is that no matter what types of signs might be chosen, we should focus on flexibility in thinking, beyond linguistic barriers and limitations. Surprisingly, since the past usually opposes flexibility, this is accomplished by making the past become part of the present: it is to be found in average images of everyday reality because re-capturing the values of the past helps to make it part of the present, of our present, of a generic present. Thus, canonical art forms, lifestyle, customs and myths are re-configured against the reader's expectations.

The present paper is a hands-on text analysis focusing on nominal elements chosen/viewed as being relevant by the poetic voice. They can become an abstract space, a reflection and/or trigger of the interpreter's common ground. Special attention will be paid to space markers, both deictic and anaphoric, in order to point out their contextual values which are of paramount importance in (re)configuring the common ground throughout the poem.

\section{Theoretical background}

\subsection{Accommodating opposite theoretical frames}

In communication the interlocutors use a common underlying code and also implication rules, therefore the hearer needs to inferentially construct the speakerintended meaning on the basis of both the decoded content and the context of the utterance. The poem places the reader between the opposite views of Literalism and Contextualism. The former is the positive theory of Semantic Minimalism which 
states that both the speaker and the hearer mentally access not only identical, but fully propositional semantic contents of the utterance utilized (Assimakopoulos 2008: 106): (recovered) logical form + contextual input $\rightarrow$ full propositional status; whereas the latter, Contextualism (Recanati 2004), follows the Relevance ${ }^{2}$ Theory (Sperber and Wilson 1995), which points out linguistic indeterminacy: linguistically encoded meaning never fully determines the intended proposition expressed (Carston 2002: 49).

According to Assimakopoulos (2008), the parallel and simultaneous operation of decoding and inferring results in a product (explicature) both truth-evaluable and pragmatically enriched. Language is a mixture of the logical and the psychological (Frege 1997: 243). The context sensitivity of the propositional content of an utterance is also apparent in the case of syntactic or lexical ambiguity (Assimakopoulos 2008: 111). To assign a determinate truth value to the propositional content of an utterance, the missing elements (unarticulated constituents) should be contextually supplied. In every communicative act there is a domain of discourse "with respect to which the speaker presents his/her utterance as true" (Recanati 1987: 62).

\subsection{Lexical items and the inferential process: common ground}

A lexical item itself triggers the inferential process by which it will be assigned a determinate semantic value; the reference of a definite description always depends on the domain of discourse (Recanati 1978: 1996); the relativity of reference to domains of discourse can apply to all definite descriptions (Carston 2002: 38).

A lexical item's literal meaning (its encoded content) needs to be pragmatically adjusted for the speaker's intended meaning to be constructed by the hearer (Assimakopoulos 2008: 112).

A word concept is a stable address in memory comprising three entries (Carston 2002: 321; Assimakopoulos 2008: 119): the lexical entry - the phonological and syntactic information about the lexical item that encodes a concept in natural language; the logical entry consisting of a set of inferential rules, "meaning postulates", providing the inferential processor with sets of premises and conclusions (ibidem); the encyclopedic entry - general information individually held with respect to its denotation, and arbitrarily stored in the form of full propositions, assumption schemas and mental images. Encoded conceptual contents should be psychologized; analytical truths should be treated as having a psychological dimension (Horsey 2006); an encoded concept might be pragmatically adjusted forcing us to construct an ad hoc

\footnotetext{
${ }^{2}$ Relevance is a psychological property of cognitive input to mental processing (Sperber and Wilson 1995). Processing is worth doing depending on the balance of cognitive effects and processing effort (Assimakopoulos 2008: 114). The more an utterance improves the hearer's belief system and the less effort it requires in its processing, the more relevant it will be to him (ibidem).
} 
concept in its place (Asimakopoulos 2008: 123); therefore the semantic content of a linguistic expression is best viewed as individualistic and cannot be publicly shared.

"All lexical meanings constructed by the hearer during the interpretation of an utterance can be viewed as outcomes of a single pragmatic process which fine-tunes the interpretation of virtually every word" (Wilson 2004: 344). This fine-tuning might imply pragmatically adjusting an already existing concept by constructing an ad hoc concept instead. It is what the reader is challenged to do in constructing the speaker's intended meanings in the poem.

Common ground as a pragmatic concept is primarily related to what is implicit, and to the condition of mutual awareness of the speaker and the hearer in relation to the implicit information. Mutual awareness concerns the whole situational context of communication but mostly the domain of presuppositions (common beliefs). To Assimakopoulos (2008: 257), it is a metaconcept explaining why people fail to identify their interlocutor's intentions during their conversational interactions for various reasons; something may be missing in their mental, moral, psychological, social, or linguistic makeup (Mey 2008: 257).

\section{From relevant referents to concepts; ad hoc concept reconstruction through art}

The two features necessary for the reader-interpreter to understand the poem and, through it, the reality of the poetic voice are [+perceptiveness] and [+amazement]. The former quality is explicitly required throughout the poem by the repetition of the verb to look in the imperative, making the utterances it forms part of primary performatives, i.e. directives. But it also has the role of an interpersonal pragmatic marker, pointing out relevant lexical items, some of them part of definite descriptions, whose encoded conceptual contents are psychologized, pragmatically adjusted so that the reader can construct ad hoc concepts; the act of looking does not involve only the perceptive level, but also the intellectual and affective levels: one is supposed to pay attention to the elements visualized, to focus on them and to see beyond their appearance. Sharing the discourse world, the poetic voice and the reader are in the same abstract space which contains relevant elements; hence, these elements are referred to by using polyfunctional deictics: space deictics rendering the feature [+proximal] to the text worlds (this, these) and also functioning as empathetic deictics to convey the intense emotional reaction of the speaker:

Look at this orange / Look at this actor / Look at it (the lavender rose) /Look at this chapel / Look at the moon / Look at the road / Look at these geese 
Each of these elements triggers a mental image in the reader's mind and also creates secondary spaces, text worlds. Playing with concrete referents, as can be noticed from the enumeration above, the poetic voice aims at challenging the reader to assess the degree to which the concept associated with the object still meets people's expressive needs. To do so she appeals to artistic representations and symbolic indexes. The obsolete/inadequate concept can be ad hoc reconstructed by pragmatic adjustment as a result of its artistic representations, concrete referents, but also symbolic indexes. Their interpretation is mediated by the discourse domain in the form of another sign that is symbolic in nature: the word, i.e. the name of the work of art. The whole poem proposes different allegedly average mental images whose conceptual interpretation the reader is at liberty to adjust to his/her own subjectivity.

Throughout the poem, the poetic voice creates/depicts social situations apparently of mutual awareness, but the establishment of common ground is a challenge and goes against the reader's expectations only to the extent to which expectations mean conventionalization, i.e. mental, psychological, social leveling leading to linguistic leveling. For example, the past becomes part of the present by comparing the contemporary concepts designated by the word orange (with its lexical, logical and encyclopedic entries) to the linguistic structures designating the colour blue in ancient Greece. In this case we can speak about the speaker's meaning, about encyclopedic entries processed by inferential rules so as to shape the concept by referent categorization. Not part of the basic word stock since it appeared in English in the $16^{\text {th }}$ century ${ }^{3}$, orange, the colour name, borrowed its name from the fruit, due to the feature /colour/, perceived as the most relevant among the others describing the referent, the effort of processing the meaning being minimal in relation to the cognitive effects. Had the fruit not existed, that tinge of colour, previously described by citrine or saffron in English, might not have been described by any word or anyway not by one which determines the automatic mental association fruit-colour.

Linguistic indeterminacy is illustrated by comparing the case of the word orange to the structure designating the colour blue. The situational context favored a longer linguistic structure, a compound whose deep structure represents a comparison: the name of the referent typically subjectively associated with the chromatic feature becomes part of the name of the color: wine-dark. This is an illustration of "real semantics" as Fodor (1998) defined it: "The true uses of a concept CAT are caused by actual cats." (Assimakopoulos 2008: 119) Similarly the concept BLUE was caused by actual blue(ish) objects, the role of the interpreter's subjectivity being undeniable. With orange too, the concept ORANGE was caused by actual orange fruit, all sharing the same chromatic feature.

\footnotetext{
${ }^{3}$ https://www.etymonline.com/word/orange
} 
The poetess, however, challenges the reader by appealing to and simultaneously enriching their common ground when she plays upon the meanings of the word orange, given its etymology. Actually she makes reference to the word designating the fruit as a symbol representing a work of art.

Look at this orange. When Rothko/ painted No. 12, 1954 was he thinking/ of a setting sun, or a piece of fruit?/ In every language I know,/ the word for both is the same./ In ancient Greek, there is no blue,/ so Homer said wine-dark,/ and honey was green; even the sky/ stretched like a canvas above the Aegean/ was cast in bronze. [...]

This secondary semiotic act wouldn't be possible if the decoder didn't know the literal meaning(s) of the word orange. Any symbolic use of the color in paintings is based on the conventional meanings of the word. Could this block the free use of one's imagination in the process of interpreting contextual meanings? Indirectly, this is the question raised by the poetic voice in the first stanza. The abstractization intended by Rothko is based on people's common ground: the concept denoted by the word orange was formed as a result of the categorization of extra-linguistic objects; through art, a concrete object (the painting) aims at conceptualizing all the mental images sharing the relevant feature [ + colored in orange].

conceptualized mental images (of orange tree fruit, of sunsets etc.)

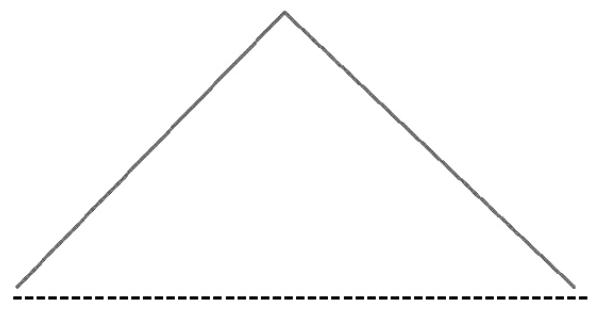

painting

class of all possible/typical referents sharing the relevant feature $[+$ colored in orange $]$

In the second stanza the deep understanding beyond words between men and their pets takes on both a physical and a behavioral representation: the beings sharing the same physical space tend to imitate one another in terms of behavior and the psychological makeup is adjusted. The concept denoted by the word $d o g$ is adjusted in its logical and encyclopedic entry:

This man is walking his dog. They are growing/ old together. The dog has learnt to walk/ like the man, or the man has been trained, by the dog,/ to walk like him. The 
man's wife, who is waiting/ in the kitchen on their third-floor walk-up watching/ waves of coffee flood the Bakelite dome of their percolator walks like the dog too. [...]

The dog becomes similar to a human being due to the latter's communicative and emotional needs: the objective truth is no longer relevant in this case, what results is a make-believe world described in the second part of the stanza. The poetess actually discusses the recategorization of dogs as part of the class of human beings based on the feature [+verbal communication], ironically as a result of a failure in communication because of the temporarily disturbed mental makeup of the dog owner (caused by drunkenness), but also of the unfulfilled psychological needs of genuine connection: $I$ once dated a Russian/mass spectometrist who said when he spoke to his dog/his dog spoke back. Brilliant, but he had a drinking problem. The profession of the man means objective minute analysis, i.e. [+perceptiveness], and more openness, resulting in his amazing concept adjustment. The concept ' dog' is adjusted and becomes unconsciously a sort of prototype for human behavior. It is an ad hoc concept that the poetic voice rejects: scientists should base their observations on facts. The ironical reaction of the poetic voice is based on her own experience, but also proves that science can become irrelevant when faced with the need to believe.

The third stanza is also an example of concept adjustment: sad experiences come to define authentic life: no suffering, no life. The theme of art reflecting life is resumed: the actor's lack of self-acknowledged sad experiences and his consequent lack of authentic life are the triggers of genuine suffering which in turn causes a radical change in his (self-)perception: his suffering is the condition of authentic life ultimately reflected in authentic art. The result is a real success, a sold-out show resulted from exposing/selling one's authenticity. The success of the performance depends on the actor's revisiting his previous condition each night, i.e. his self-perception as a man lacking dramatic life moments; each time his reflection on (his previous view on) the past is a source of dramatism. Life and art overlap, the borderline between them is blurred. The situational context triggers the conceptual adjustment:

[-suffering $]$ life $>[$-authentic $]$ art $>[+$ suffering $]$ life $>[+$ authentic $]$ life/art.

Look at this actor. He is the protagonist of a terrible tragedy.

$\mathrm{He}$ is using the Stanislavsky technique to play the part.

Right before the third act, the director instructs him to cry.

The actor tries to think of something sad; he tries to remember

a time in his life when he had the blues so bad he was almost

broken, but he thinks of nothing. In that moment, the actor realizes

he has not truly lived, and is overwhelmed by sadness.

He uses this method every night to a sold-out show. 
The actor identifies himself with the role and his life devoid of sad events is turned into a concept which creates the desired state, only it is not faked but totally authentic, characterizing both the character and the new man the actor has become; conceptually life overlaps art and they share the feature [+suffering]:

1. situational context

[-suffering] life / [- authentic] art

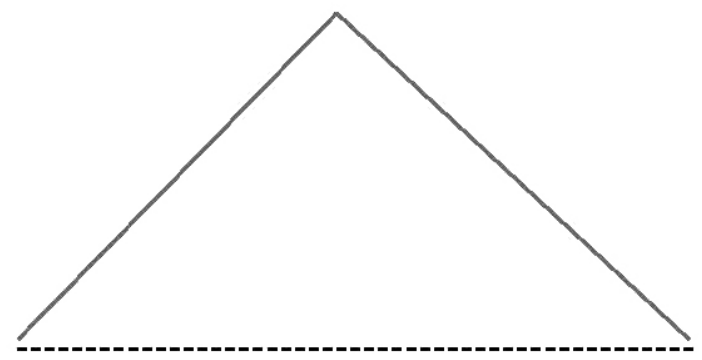

Actor

[- authentic] character ${ }_{1}$

$[+$ atypical $] \operatorname{man}_{1}$

2. ad hoc concept construction

[+suffering $]$ life / [ + authentic $]$ art

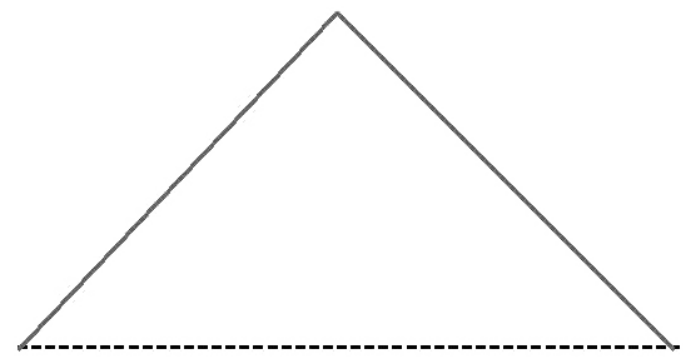

Actor

[+ authentic] character 2

[+atypical] $\operatorname{man}_{2}$ 
The play upon authentic vs. fake continues in the fourth stanza, the topic being genetic engineering, more precisely the aim of creating a blue rose. The result was in fact a lavender rose, "in itself something else", since lavender is not proper blue. Differences lie in small details, which subjectively might prove fundamental. Though almost perfect, the new creation seems unnatural to the poetic voice's perception, this flower being compared to a glass masterpiece, i.e. to a conventional artificial beauty representation. Could inflexibility in thinking, instantiated in the rigid purposes selfimposed by people, prevent us from seeing the essence of our deeds and become unable to differentiate success from failure? The rose aura can be seen only if one gets in touch with one's spirituality. God's perfection is observable in any form, flowers and glassware included:

The Australians and the Japanese have collaborated/ to genetically engineer a blue rose. The experiment has failed./ The rose is lavender (itself another thing)/ with an aura at its edges that looks glass-blower blue./ Look at it. One might say it's approaching perfection.

Stanzas 5 and 9 make reference to the physical space of the chapel as a spiritual space, its spirituality transcending time. The chapels referred to belong to a well-defined spiritual culture, that of the Catholic world, and to a geographical area equally welldefined either explicitly (Madrid, Spain in stanza 5) or implicitly (presumably Italy, where there is a real cult for Saint Anthony, in stanza 8). The deictic spiritual spaces created in the text include the reader within them, while the absolute space reference facilitates the 'standard' decoding of the concept of church as an encyclopedic entry.

Stanza 5 opposes the spiritual space of the church, with the ironical-joyful image of Goya, a symbol of artistic mastery and of intense authenticity, to that of the tourists indulging in the savory dishes of the restaurant nearby, once a famous cider house:

Look at this chapel. It stands next to Casa Mingo, the oldest cider house in Madrid.

The cider house is now a restaurant/ famed for its roasted chicken.

One sits at the wooden trestle tables/ wresting flesh from bone/ while Goya's ghost waves frantically/ from the chapel's steeple.

His waving frantically could mean acknowledging the present time and the propensity of today's people for the joys of material life: the chapel standing next to the oldest cider house in Madrid is the best metaphor for the dual nature of human existence. The concept of faith is turned into an ad hoc concept, including material life joys, and literally turning the chapel building into a(n) (up)lifting space of connection over time.

The idea of accommodating material and spiritual life is resumed in the eighth stanza where faith (and the image of the chapel as a place for prayer) is linked to 
blessed marriage, as a condition of human happiness (at least for women, as it appears). The women's prayers concern their earthly existence and they pray to Saint Anthony to bring them husbands: the concept of faith has been psychologically adjusted to meet personal and social needs: the object of desire and prayer is absent from this holy space. Instead, the men are to be found in a field catching lizards.

On the 13th of June every year,/ young women come to the chapel to pray to Saint Anthony/ for a husband. For their part, the husbands/ are elsewhere. They are in a field catching lizards.

To the average reader, the mundane image of the field with lizards might connote an inclination towards nature, simple things, and material life in general. But in Mediterranean cultures, the concept of lizard is a familiar element, [-hierarchydependent], a friend of one's home (Chevalier and Geerbrant 1969: 320); moreover, in the Bible (Parables 30, 24) it is a symbol of ecstatic contemplation, one of the smallest and also wisest creatures, humbly looking for light (idem: 321). The poetic voice revisits these old myths and creates an ad hoc concept of lizard full of spiritual facets. Although both men and women might seek spirituality, they do so in different ways and in different spaces. Projecting their limited desire through prayers, women unify the spiritual and the earthly space.

Stanza 6 brings the reader back to the world of science, better said of astronomy, making reference to the moon, not as a romantic symbol but as a material reality reached by the astronomers for the first time in the late 1960s. Through the image of Neil Armstrong, one of the first astronauts to have ever walked on the surface of the moon, the poetic voice creates an ad hoc concept of astronaut, having the features [+Earth's everyday life-anchored], [ + sensuous perception of reality]. The clear identity of the astronaut is revealed both directly and indirectly by the reference made to his wife, Carol, a fact which elicits the reader's encyclopedic knowledge. The way of perceiving the moon is somehow challenged and this new reality tends to be approached in terms of olfactory information. Is it (self)-irony? The play upon essence and appearance is represented by a mental image meant to create an ad-hoc concept. The ad hoc concept triggers the amazement of the reader: the moon was perceived distinctly in relation to the subjective olfactory memory of earthly realities, maybe in an attempt to highlight our limitations but also our means of turning something unfamiliar into something familiar; the empathetic deictics this and it in the last verse perform this role:

Look at the moon. Apparently, some men/ have walked on it. I wonder/ what it smelled like up there./ I wonder if Neil, walking/ around the farmer's market/ on a crisp Sunday morning,/ dog leash in one hand, wife's purse/ in the other, paused by an apple/ or a bunch of parsnips, and said,/ Carol, this is it! I haven't smelled the moon in years! 
The themes tackled in stanza 7 are art in art, tattooing in a film, and also love as an artistic representation; this facet of the concept of love is challenged since the canvas is a female artist's lovers' skin. Perishable and thus making art perishable too, in its concrete occurrences. The final part of the stanza advocates against accepting this perishability and creating/maintaining an after-death cult of physical beauty to make it visible to all. The ad hoc concepts of beauty having the seme [+/- living referent] and art objects as [+human] appear within an artistic representation of the world, itself a possible real life reflection. It is the reflection of the poetic voice's world, where the deictic pronoun $I$ re-establishes the direct dialogue with the reader:

In this film, a woman practices the art of calligraphy/ on her lovers' skin. She is not always pleased with them;/ too oily, too dry, too much hair, too wrinkled./ Then she meets Jerome, whose skin (and everything else)/ until he meets his tragic end, is perfect. I have often wondered/ why we bury or burn our dead. For those who die young/and whose beauty has not yet abandoned them,/ there ought to be something else.

In stanza 8, starting from the literal meaning of the word road and from the technical definition of perspective, the poetic voice implies the figurative meaning of the words road, perspective, and see. The perspective means the end, the result of the journey, if it is limited, so would the results be. But the journey proper activates the conventional metaphor LIFE IS A JOURNEY, which is not so much about the results, as it is about enjoying the journey itself, expecting the unexpected. Short eye-sight does not mean 'short mind-sight', since not knowing what lies ahead is what motivates people on their way, precisely because they can imagine it.

Look at the road. It runs 100 miles in the same direction

yet we can only see a few hundred feet ahead. They call this

a trick of perspective. I wonder, though, if we could glimpse

the end, would we have the energy or courage to travel it?

Stanza 10 continues somehow the theme and concept of the road. Trains mean a limited physical space which can generally imply a conventional spiritual space. But if the concept is adjusted to designate a socio-psychological component, trains correspond to the social status and limit social interaction:

Two trains leave the station at the same time.

One is a luxury express. Its seats are upholstered

with full-grain leather, the kind that smells like

spice-box and pine, and it's dining car,

open all day and night, serves crust-less tea sandwiches 
and real French champagne. The other is a slow-going freight train. It has a small, cramped car for passengers

who purchase their tickets at a discounted fee, and along the way makes several stops, hefting goods onto and from its wagons.

Though both trains arrive at the same destination, it is unlikely they'll ever pass each other.

Contrasted to the unlimited spiritual space, trains different as they may be, are actually mental spaces meant to make the passengers enjoy the journey, without thinking about the destination. Trains, cars, the station, though limited as physical spaces, can be excellent triggers of spiritual unlimitedness; boxlike, train cars can make one unable to 'think outside the box', but this is not an unavoidable consequence. How one gets to the destination is what matters.

The ad hoc concept of the last stanza is represented by the geese placed in a deictically definite, yet ambiguous setting (here, in August), whose amazing expected referents the flocks of wild geese are. The subjective spiritual space is emphasized by person deictics, but also by the adjusted concept in its logical and encyclopedic entries:

Look at these geese. It is common here, late August, to see/flocks of them scattered like river stones across a park/ or patch of grass on the side of a busy road. Wild animals./It is not uncommon, but amazes me every time./Things like this amaze me every time.

Comparing the geese to river stones, the poetic voice views these wild animals as guardians, witnesses, companions, reactivating old beliefs. Since ancient times, they have been considered as the basis of our existence, their wilderness as unlimited desires and energies released, abandoning and then returning to, their home. Viewed in mythologies as messengers between Earth and Heaven (for the Egyptians and Chinese) (Chevalier and Geerbrant 1969: 98), these solar animals remain a symbol of the family. The ad hoc concept created by the poetic voice combines old beliefs with the subjective feelings of familiarity and amazement, the two features found throughout the whole poem.

\section{Hazardous ordering of "snapshots" or covert structuring of mental images?}

Should we expect to submit a postmodern poem like A New New Guide to an interpretation tributary of the structural constraints whose opposite it represents? The mental images proposed are meant to raise and challenge our awareness regarding 
them, since they are turned into artistic representations, but also into precursors of new/ adjusted concepts. There is a set of 11 stanzas, 11 snapshots, mental images apparently selected at random, but which pragmatically adjusted to the subjectivity of the poetic voice and to that of the reader can make up a covert structure. They are all everyday life images, if not seen directly, then certainly repeatedly noticed due to the various media. Typically socially or psychologically constructed concepts exert their pressure on the individual (including on their social dimension) and in the clash between the atypical(ly perceived) reality and the conventional concept, a cathartic ad hoc concept may be created.

The table below summarizes these context-dependent semantic changes of the key words in the text, putting together their significations, i.e. relevant referents (now triggers of new categorizations), the concepts typically designated by them and the new ad hoc concepts with their unexpected distinctive semes.

\begin{tabular}{|c|c|c|}
\hline $\begin{array}{l}\text { Relevant referent, } \\
\text { part of (a)typical } \\
\text { contemporary } \\
\text { reality }\end{array}$ & General concept designated & Ad hoc concept distinctive feature \\
\hline Orange & art (painting) & $\begin{array}{l}\text { Relative reference (relativity of the } \\
\text { referent recovering) in the case of } \\
\text { concepts turned into artistic symbols }\end{array}$ \\
\hline Man, dog & $\begin{array}{l}\text { life vs. science (genetics, } \\
\text { psychology and communication) }\end{array}$ & $\begin{array}{l}\text { Dogs as [+human behavior] referents } \\
\text { Humans as [+doglike behavior] } \\
\text { referents }\end{array}$ \\
\hline Actor & $\begin{array}{l}\text { art (theatrical productions) vs. } \\
\text { life }\end{array}$ & $\begin{array}{l}\text { Suffering as a [ }+ \text { creating reality] } \\
\text { concept in the real world and in the } \\
\text { fictional world }\end{array}$ \\
\hline Lavender rose & $\begin{array}{l}\text { science (genetic engineering) } \\
\text { vs. life }\end{array}$ & $\begin{array}{l}\text { Science as a [+recategorizing reality] } \\
\text { concept }\end{array}$ \\
\hline $\begin{array}{l}\text { Chapel }_{1} \\
\text { Chapel }_{2}\end{array}$ & $\begin{array}{l}\text { art and religion (spirit) vs. life } \\
\text { (style)/matter, (anti)tradition } \\
\text { religion and life within a } \\
\text { catholic space, cultural and } \\
\text { implicitly conceptual in the } \\
\text { forms of beliefs }\end{array}$ & $\begin{array}{l}\text { Spiritual space as a }[+ \text { materiality } \\
\text { oriented] [sensually perceived] space }\end{array}$ \\
\hline Moon & science (astronomy) vs. life & $\begin{array}{l}\text { Outer space reality as familiar sensua } \\
\text { perception }\end{array}$ \\
\hline
\end{tabular}


Claudia Pisoschi

\begin{tabular}{|l|l|l|}
\hline Film, tattoos & $\begin{array}{l}\text { art in art (tattooing in films) - } \\
\text { perfection vs. life (its earthly end } \\
\text { i.e. end of physical perfection) }\end{array}$ & $\begin{array}{l}\text { The concept of (artistically relevant) } \\
\text { human beauty excluding the feature } \\
\text { [+living] }\end{array}$ \\
\hline Road & $\begin{array}{l}\text { life as a physical space, as a } \\
\text { symbolic journey with a limited } \\
\text { perspective and a certain end }\end{array}$ & $\begin{array}{l}\text { Limited visual perspective as a trigger } \\
\text { of unlimited mental vision }\end{array}$ \\
\hline Geain cars, station & $\begin{array}{l}\text { life as a journey, journeys as } \\
\text { an applied mechanics issue, } \\
\text { life view }\end{array}$ & $\begin{array}{l}\text { Social distance as a concept in which } \\
\text { physical distance is no longer relevant }\end{array}$ \\
\hline life vs. myth & $\begin{array}{l}\text { [-human] referents as human life } \\
\text { witnesses and guardians }\end{array}$ \\
\hline
\end{tabular}

Table 1. Context-dependent semantic changes of the key words

We are discussing not the classical hierarchy of stanzas but a subjective one, with the snapshots repeating themes on a higher level, and triggering new reactions, and new reconceptualizations. Sensuous perception appears both as a trigger and as a purpose; psychologically perceived reality shapes concepts to the same extent to which the latter can recategorize our perception of reality. The cohesion and coherence of the whole text exists at the level of pragmatic inferences, and is interpreter-dependent.

\section{Conclusions}

The poem is the expression of the thought's free movement in space and time: past and present unify beyond any limitations. The mental images presented as 'snapshots' are triggers of our conceptual awareness, but also substance re-configured to create ad hoc concepts based on pragmatic inferences and corresponding to reality perceived psychologically.

The all-encompassing implicit key concept is relativity, applied to canonical forms, 'standard' meanings and hierarchies; hence, the message repeatedly expressed by the verb look in the imperative is 'look beyond appearances', i.e. 'think' and conceptualize in context. Relativity is at work throughout the poem mainly in the play upon the opposition concrete-abstract: referent vs. concept, life vs. art, all sharing the common feature [+creation].

This perspective makes the reader realize that the word guide in the title refers not to a person acting as such, but to a personal code of ad hoc concepts which are amazing reinterpretations of what people consider to be familiar 'anchors' (everyday images, facts, symbols). Everybody can make their own guides which will represent a new approach to their (human) condition and directions in life, given a constant attitude of openness and amazement in relation to any form of creation. 


\section{References}

Assimakopoulos, S. (2008). Intention, Common Ground and the Availability of Semantic Context: a Relevance - Theoretic Perspective. In: I. Kecskes and J. Mey (eds.), Intention, Common-Ground and the Egocentric Speaker-Hearer, Berlin and New York: Mouton de Gruyter, 105-126. (8 February 2019) < http:// doi.org/10.1515/9783110211474.1.105>.

Carston, R. (2002). Thoughts and Utterances. The Pragmatics of Explicit Communication. Oxford: Blackwell.

Chevalier, J. and A. Geerbrant (1969). Dictionnaire des symbols. Mythes, rêves, coutumes, gestes, forms, figures, couleurs, nombres. Vol. I-III. Paris: Éditions Robert Laffont S. A. [the Romanian version coordinated by M. Slăvescu \& L. Zoicaș, Bucarest: Artemis Publishing House, 1993].

Egger, L. A New New Guide. (3 March 2018) <http://friendsofwriters.org/2017/05/30/ a-new-new-guide-by-lara-egger-poetry-16/> .

Fodor, J. A. (1998). Concepts. Where Cognitive Science Went Wrong. New York: Oxford University Press.

Gross, S. (2001). Essays on Linguistic Context-Sensitivity and its Philosophical Significance. New York: Routledge.

Horsey, R. (2006). The Content and Acquisition of Lexical Concepts. Unpublished $\mathrm{PhD}$ dissertation. University College London.

Mey, J. (2008). "Impeach or exorcise?" Or, what's in the (common) round? In: I. Kecskes and J. Mey (eds.), Intention, Common-Ground and the Egocentric Speaker-Hearer, Berlin/New York: Mouton de Gruyter, 255-275. (8 February 2019) <http://doi.org/10.1515/9783110211474.1.105>.

Recanati, F. (2004). Literal Meaning. Cambridge: Cambridge University Press.

Sperber, D. and D. Wilson (1995). Relevance, Communication and Cognition. $2^{\text {nd }}$ edition. Oxford: Blackwell.

Stanley, J. (2000). Context and Lexical Form. Linguistics and Philosophy, 23, 391434.

Wedgwood, D. (2007). Shared Assumptions. Semantic Minimalism and Relevance Theory. Journal of Linguistics, 43, 647-681.

Wilson, D. (2004). Relevance and lexical pragmatics. UCL Working Papers in Linguistics, 16, 343-360. 